\title{
DETERMINING THE MOISTURE TRANSFER PARAMETERS DURING CONVECTIVE DRYING OF SHRIMP
}

\author{
M. V. C. SILVA ${ }^{1}$, R. C. PINHEIRO' ${ }^{2}$, L. H. M. $\operatorname{SILVA}^{2}$ e A. M. C. RODRIGUES ${ }^{2}$ \\ ${ }^{1}$ Universidade Federal do Pará, Faculdade de Engenharia Química \\ ${ }^{2}$ Programa de Pós-Graduação em Ciência e Tecnologia de Alimentos - UFPA \\ E-mail para contato: marcus.ufpa@yahoo.com.br
}

\begin{abstract}
In the present work, the mass transfer parameters, namely moisture diffusivity and moisture transfer coefficient, of shrimp samples were evaluated by the analytical model proposed by Dincer and Dost. As part of the experimental work, the shrimps were submitted to boiling, in salt solution before drying. The experiments were performed under controlled conditions of drying air at temperature of $60^{\circ} \mathrm{C}$ and velocity of $1.5 \mathrm{~m} / \mathrm{s}$. Experimental dimensionless moisture content data were used to calculate the drying coefficients and lag factors, which were then incorporated into the analytical model for slab and cylinder shapes. The results showed a reasonably good agreement between the values predicted from the correlation and the experimental observations $\left(\mathrm{R}^{2}>\right.$ 0.9800 and $\left.\chi^{2}<1.27 \times 10^{-3}\right)$. Biot number, effective moisture diffusivity and mass transfer coefficient were computed and ranged between $0.1351-0.2384,1.001 \mathrm{x}$ $10^{-8}-2.96 \times 10^{-8} \mathrm{~m}^{2} / \mathrm{s}$ and $4.369 \times 10^{-7}-13.290 \times 10^{-7} \mathrm{~m} / \mathrm{s}$, respectively.
\end{abstract}

\section{INTRODUCTION}

Dried shrimp is one of the most important fishery products in north coast of Brazil (Pará State). Its price depends on shrimp qualities such as color, size, dryness and taste. Commonly the production of dried shrimp can be divided into two steps: boiling shrimp with salt water (in order to deactivate microorganisms) and then it is dried in the sun for 3-5 days. Although the open sun-drying method represents a low cost processing technique, it has limitations such as the control of the drying process and parameters, weather uncertainties and large drying area. Moreover, the products are prone to microbial and other contaminations that adversely affect the product quality in terms of color, nutrition, chemical composition and food hygiene (Koc et al., 2004; Ergunes and Tarhan, 2006). For commercial producers, the ability to process continuously with reliability is important to satisfy their markets. The drying of food materials by the use of heated air has advantages on quality control, on achievement of hygienic conditions, and on reduction of product loss.

Dincer and Dost $(1995,1996)$ developed and verified analytical techniques for characterizing the mass transfer in geometrically and irregularly (by use of a shape factor) shaped objects during drying. New drying parameters, namely drying coefficients and lag factors, were introduced based on an analogy between cooling and drying profiles, both of which exhibit an exponential function with time. The model was applied to slab shaped wood samples subjected to drying, with the results indicating that the technique was capable of determining the moisture diffusivities and moisture transfer coefficients in a simple and 
accurate manner for practical applications, and would be beneficial to the relevant drying industries (Dincer, 1998). Using the experimental data, the aim of this work is to determine the moisture diffusivity and moisture transfer coefficients for shrimp subjected to convective drying using the analytical model developed by Dincer and Dost (1995). As the shrimp has irregular shaped, correlations for slab and cylinder shapes were tested in this study to estimate the moisture transfer parameters.

\section{MATERIALS AND METHODS}

\subsection{Raw material}

The material tested in the present study was wild shrimp of the genus Macrobrachium amazonicum. Raw shrimp were caught off the north coast of Brazil (Pará State) in November 2013 with different sizes. The shrimps were placed in ice with an ice/shrimp ratio of 2:1 (w/w) and transported to the Laboratory of Food Technology of Federal University of Pará. Upon arrival, the shrimps were washed with clean water, graded and subjected to glazing process. After glazing process, shrimp samples were packaged and stored $\left(-18^{\circ} \mathrm{C}\right)$.

\subsection{Boiling shrimp and liquid smoking process}

Before each experiment, the shrimps were thawed at $5^{\circ} \mathrm{C}$, beheaded and washed, to decrease the number of microorganisms to a safe level and to improve the appearance of final product. Afterwards, the samples were immersed in boiling salt solution $7 \%(\mathrm{w} / \mathrm{v})$ that was inserted in a $15 \mathrm{~cm}$ diameter stainless steel vessel for seven minutes and the mass ratio of shrimp to salt solution was of 1:5 on the weight basis. The commercial size of classification $61 / 70$ of raw beheaded shrimp was used in each boiling experiment. Afterwards, the samples were cooled at ambient air for $5 \mathrm{~min}$, deshelled and then subjected to liquid smoking process, where, the samples were immersed in liquid smoke solution $2 \%$ for 20 seconds.

\subsection{Drying experiments}

The drying processes were carried out in a convective tray dryer, with drying airflow of $1.5 \mathrm{~m} / \mathrm{s}$ and air temperature of $60^{\circ} \mathrm{C}$. Three sets of drying experiments were performed with shrimps beheaded and deshelled. The first one, with shrimp without boiling (WB). The second set, with shrimp boiled in salt solution (SB). The third set, with shrimp boiled in salt solution and subjected to liquid smoking process (SBS). About $150 \mathrm{~g}$ of samples were placed in a stainless steel basket, which was suspended on a balance with an accuracy of $\pm 0.01 \mathrm{~g}$, communicated with an interface system connected to a personal computer, which recorded and stored the weight changes in real time (measured every $10 \mathrm{~min}$ ).

\subsection{Data analysis}

The moisture diffusion process observed during the drying operation is governed by the Fickian equation. By adopting a number of assumptions, e.g.: thermophysical properties of the solid and the drying medium are constant; the effect of heat transfer on the moisture loss is negligible and the moisture diffusion occurs in one-direction (perpendicular to the slab 
surface, the transient moisture diffusivity equation in cartesian coordinates and in dimensionless form can be written as (Dincer and Hussain, 2002):

$$
\begin{aligned}
& \frac{\partial \Phi}{\partial t}=D \frac{\partial}{\partial y}\left(\frac{\partial \Phi}{\partial y}\right) \\
& \Phi=\frac{W-W_{e}}{W_{i}-W_{e}}
\end{aligned}
$$

where $W$ is moisture content by weight as dry basis $(\mathrm{kg} / \mathrm{kg}), D$ is moisture diffusivity $\left(\mathrm{m}^{2} / \mathrm{s}\right), t$ is time (s), $y$ is space coordinate measured from center of the board and $\Phi$ is dimensionless moisture content.

Equation (1) is subject to the following initial and boundary conditions:

$$
\begin{aligned}
& \Phi(y, 0)=1 \\
& (\partial \Phi(0, t) / \partial y)=0 \\
& -D(\partial \Phi(L, t) / \partial y)=h_{m} \Phi(L, t) \quad \text { for } 0.1 \leq \mathrm{Bi} \leq 100, \Phi(\mathrm{L}, \mathrm{t})=0 \text { for } \mathrm{B}>100
\end{aligned}
$$

The solution of the governing Eq. (1) with the boundary conditions yields dimensionless center moisture distribution for regular shaped objects in the following form:

$$
\Phi=\sum_{n=1}^{\infty} A_{n} \cdot B_{n}
$$

The above solution can be simplified if the values of $\left(\mu_{1}^{2} F_{o}\right)>1.2$ are negligibly small. Thus, the infinite sum in Eq. (6) is well approximated by the first term only, i.e.:

$$
\Phi \cong A_{1} B_{1}
$$

where for slab shapes:

$$
A_{1}=\exp [0.2533 B i /(1.3+B i)]
$$

for cylindrical shapes:

$$
A_{1}=\exp [0.5066 B i /(1.7+B i)]
$$

and for all objects:

$$
B_{1}=\exp \left(-\mu_{1}^{2} F_{o}\right)
$$


Dincer and Dost (1996) proposed the following exponential equation for the objects subject to drying, by introducing lag factor ( $G$, dimensionless) and drying coefficient $(S, 1 / \mathrm{s})$ :

$$
\Phi=G \exp (-S t)
$$

Drying coefficient shows the drying capability of an object or product per unit time and lag factor is an indication of internal resistance of an object to the heat and/or moisture transfer during drying. These parameters are useful in evaluating and representing a drying process. The values of the dimensionless moisture content can be obtained using the experimental moisture content measurements from Eq. (2).

Both Eqs. (7) and (11) are in the same form and can be equated to each other by having $G=A_{l}$. The moisture diffusivity $(D)$ for slab and cylindrical shapes is given by the following equation (Dincer and Dost, 1996):

$$
D=\frac{S Y^{2}}{\mu_{1}^{2}}
$$

where $Y$ is the characteristic dimension (half-thickness for slab, radius for cylinder) and $\mu_{1}$ is a root of solution to the moisture diffusivity, that is given as (Dincer and Hussain, 2002):

for slab geometry,

$$
\mu_{1}=a \tan (0.640443 B i+0.380397)
$$

for cylindrical geometry,

$$
\mu_{1}=((3 / 4.188) \ln (6.796 B i+1))^{1 / 1.4}
$$

In this solution, the dimensionless parameters used are the Biot number $\left(B_{i}\right)$ and the Fourier number $\left(F_{o}\right)$, which are defined as:

$$
\begin{aligned}
& B_{i}=\frac{h_{m} \cdot Y}{D} \\
& F_{o}=\frac{D \cdot t}{Y^{2}}
\end{aligned}
$$

where $h_{m}$ is the moisture transfer coefficient.

\subsection{Statistical analysis}

Analysis of variance (ANOVA) was conducted to determine the effect of variable factors on drying parameters. The parameters of analytical model proposed by Dincer and Dost (Eq. (11)), were estimated using the software Statistic for Windows 7.0 (StatSoft Inc., Tulsa, OK, USA). The fit quality of the proposed models for the drying kinetics data was estimated by means of the correlation coefficient $\left(\mathrm{R}^{2}\right)$ and Chi-squared parameter $\left(\chi^{2}\right)$. 


\section{RESULTS AND DISCUSSION}

The profiles of experimental moisture ratio as function of time during drying of shrimp samples obtained at different conditions of processes are shown in Fig. 1. The drying rate of removal of moisture for WB samples was lower than the samples SB and SBS. This result is because of the heat-induced denaturation of proteins during boiling in salt solution, which in turn led to lower water-holding capacity, of the shrimp samples. The drying rate of removal of moisture for samples SBS was lower than the samples SB, though it has also been subjected to boiling. This behavior can be attributed to changes on the tissue structure of the shrimp caused by the incorporation of compounds present in the composition of the extract smoke, such as phenolic derivatives, carbonyls and organic acids, which resulted in a type of coating of the surface of the shrimp, contributing in reduction of moisture movement.

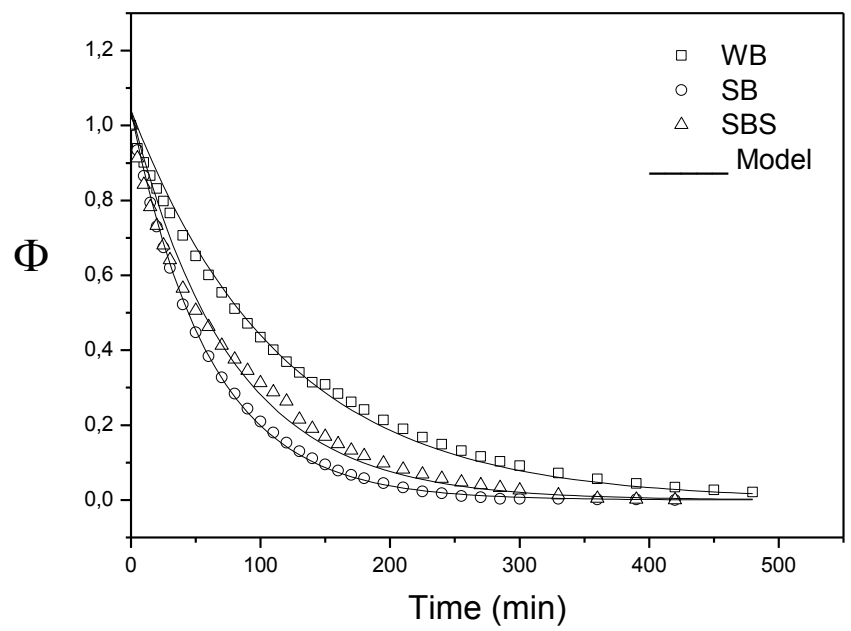

Figure 1 - Experimental average dimensionless moisture content of shrimp

The dimensionless moisture content values were regressed against the drying time in the exponential form of Eq. (11), using the least squares curve fitting method and good fits were obtained for all drying conditions $\left(\mathrm{R}^{2}>0.98\right.$ and low $\chi^{2}$ values). This indicates that the main mechanism of water transport is diffusion and the diffusion equation (Eq. (11)) may be applied to the analysis of drying data (Saravacos and Maroulis, 2001). Thus, the drying coefficients (S) and lag factors $(\mathrm{G})$ were determined as presented in Table 1.

Table 1 - Drying coefficient, lag factor and statistical parameters values

\begin{tabular}{ccccc}
\hline \multirow{2}{*}{ Drying condition } & \multicolumn{2}{c}{ Model coefficients } & \multicolumn{2}{c}{ Statistical parameters } \\
\cline { 2 - 5 } & $\mathrm{G}$ & $\mathrm{S}\left(\mathrm{s}^{-1}\right)$ & $\mathrm{R}^{2}$ & $\chi^{2}$ \\
\hline WB & 1.0401 & $1.43 \times 10^{-4}$ & 0.9932 & $6.20 \times 10^{-5}$ \\
SB & 1.0390 & $2.18 \times 10^{-4}$ & 0.9857 & $1.27 \times 10^{-3}$ \\
SBS & 1.0380 & $2.76 \times 10^{-4}$ & 0.9987 & $1.24 \times 10^{-4}$ \\
\hline
\end{tabular}


The drying coefficient (S) is a parameter which indicates the drying capability of the solid object and has a direct effect on the moisture diffusivity. ANOVA showed significant differences $(\mathrm{P}<0.05)$ in $\mathrm{S}$ values caused by different pretreatments applied before drying. The value of the drying coefficient is highest for samples SB and was lowest for WB. These results demonstrate that boiling had a significant effect not only on the quality of shrimp, but also on the drying kinetics. Changes in the cellular structure of the material (denaturation and coagulation of protein) resulted in improvement in the rate of moisture removal from it. The values of $\mathrm{S}$ obtained in this study are in the same range of the values found by Corzo et al. (2008), for the drying of mango slices at different maturity stages, ranging between $2.49 \times 10^{-4}$ to $7.64 \times 10^{-4} \mathrm{~s}^{-1}$ and they are also of the same magnitude of that reported by Akpinar and Dincer (2005) for eggplant slabs subjected to convective drying, ranging between $2.04 \times 10^{-4}$ to $3.82 \times 10^{-4} \mathrm{~s}^{-1}$.

The lag factor $(\mathrm{G})$ gives an indication of the magnitude of the internal resistance to moisture transfer and has a direct effect on the moisture transfer coefficient as a function of the Biot number (Dincer and Dost, 1996). For the three pretreatment, all lag factors (G) were higher than 1 (Table 1), leading to the Biot number in the range $0.1<\mathrm{Bi}<100$, indicating the presence of the external and internal resistance to moisture transfer.

Using the calculated lag factor, the Bi number for each experimental condition was determined using Eqs. (8) or (9), as appropriate. Subsequently the associated values of $\mu_{1}$ for moisture transfer were computed from the simplified expressions for a slab and cylinder, Eqs. (13) and (14), respectively. The calculated Biot numbers and $\mu_{1}$ values are shown in Table 2. ANOVA showed significant differences $(\mathrm{P}<0.05)$ in $\mathrm{Bi}$ values caused by different pretreatments applied before drying. The values of the Bi obtained in this study were of the same magnitude of that reported by several authors, from 0.100 to 0.108 for the drying of mango slices (Corzo et al., 2008), 0.1020 to 0.2026 for the drying of pears (Guiné et al., 2013), 0.2060 to 0.3228 during convective drying of broccoli (Mrkic et al., 2007).

Table 2 - Biot numbers and $\mu_{1}$ values

\begin{tabular}{ccccc}
\hline \multirow{2}{*}{ Drying condition } & \multicolumn{4}{c}{ Drying parameters } \\
\cline { 2 - 5 } & Slab & Cylinder & Slab & Cylinder \\
\cline { 2 - 5 } & 0.2384 & 0.1430 & 0.4900 & 0.5977 \\
WB & 0.2245 & 0.1351 & 0.4828 & 0.5801 \\
SB & 0.2313 & 0.1389 & 0.4862 & 0.5886 \\
\hline
\end{tabular}

Using the values of $Y, S$ and $\mu_{1}$, the moisture diffusivity $(D)$ was then computed by Eq. (12). Subsequently the values of moisture transfer coefficient $\left(h_{m}\right)$ were computed by Eq. (15). The values of $D$ and $h_{m}$ are presented in Table 3. Values of $D$ for all drying conditions varied from $1.489 \times 10^{-8}$ to $2.960 \times 10^{-8} \mathrm{~m}^{2} \mathrm{~s}^{-1}$ for slab, and $2.960 \times 10^{-8}$ to $2.050 \times 10^{-8} \mathrm{~m}^{2} \mathrm{~s}^{-1}$ for cylinder. These values are within the normally expected range of $D\left(10^{-12}\right.$ to $\left.10^{-8} \mathrm{~m}^{2} \mathrm{~s}^{-1}\right)$ for dehydrated foods (Giovanelli et al., 2002; Gely and Santalla, 2007). This variability depends on the types and conditions of experimental procedures used for determination of the $D$, data 
treatment methods and structure complexity of foods (Dincer and Hussain, 2002). An ANOVA test revealed significant influence of different pretreatments applied before drying (P $<0.05)$ in $D$ values. It was observed that the $D$ value for WB is lower $(\mathrm{P}<0.05)$ than the SB and SBS, but there is no big difference $(\mathrm{P}>0.05)$ in $D$ for the pretreatments SB and SBS.

Table 3 - Moisture diffusivity and moisture transfer coefficient values

\begin{tabular}{ccccc}
\hline \multirow{2}{*}{ Drying condition } & \multicolumn{4}{c}{ Drying parameters } \\
\cline { 2 - 5 } & \multicolumn{2}{c}{$\mathrm{D} \times 10^{8}\left(\mathrm{~m}^{2} / \mathrm{s}\right)$} & \multicolumn{2}{c}{$\mathrm{h}_{\mathrm{m}} \times 10^{7}(\mathrm{~m} / \mathrm{s})$} \\
\cline { 2 - 5 } W & 1.489 & Cylinder & Slab & Cylinder \\
\hline WB & 1.001 & 7.113 & 2.863 \\
SBS & 2.960 & 2.050 & 13.290 & 5.539 \\
\hline
\end{tabular}

Values obtained of moisture transfer coefficient $h_{m}$ (Table 3) ranged between $7.113 \mathrm{x}$ $10^{-7}$ to $13.290 \times 10^{-7} \mathrm{~m} / \mathrm{s}$, and $2.863 \times 10^{-7}$ to $5.539 \times 10^{-7} \mathrm{~m} / \mathrm{s}$, respectively for slab and cylinder shape. These results are in the same range of those available in the existing literature for different foods and drying conditions, such as reported by Demirel and Turhan (2003), 6.0 $\times 10^{-7}$ to $15.10 \times 10^{-7} \mathrm{~m} / \mathrm{s}$ during drying of banana slices; Tripathy and Kumar (2009), $1.61 \mathrm{x}$ $10^{-7}$ to $4.17 \times 10^{-7} \mathrm{~m} / \mathrm{s}$ during drying of potato in cylindrical shape; Dincer and Hussain (2004), $12.226 \times 10^{-7} \mathrm{~m} / \mathrm{s}$, during drying of onion slices; Tsami and Katsioti (2000), $4.026 \mathrm{x}$ $10^{-7} \mathrm{~m} / \mathrm{s}$, during drying of prune slices. This is an important drying parameter that depends on moisture diffusivity, viscosity, velocity of the fluid and the geometry of the transfer system (Saravacos and Maroulis, 2001).

In the literature, determination of moisture transfer coefficient for fishery products is scarce, even though it is significantly important in the evaluation of mass transfer or simultaneous heat and mass transfer processes. The ANOVA test showed significant differences $(\mathrm{P}<0.05)$ in $h_{m}$ values caused by different pretreatments applied before drying. It was observed that the $h_{m}$ value for WB is lower $(\mathrm{P}<0.05)$ than the SB and SBS.

\section{CONCLUSIONS}

The results of this study indicate that the model developed by Dincer and Dost (1995) is an effective means and capable to calculate the moisture diffusivity and moisture transfer coefficient values for convective drying of shrimp at different conditions of pretreatments applied before drying. It was also observed that pretreatments applied have a significant effect on drying rates for shrimp samples. Therefore it is recommended boiling as a pretreatment during the drying of shrimp because it reduces the time and rate of drying.

\section{REFERENCES}

AKPINAR, E. K.; DINCER, I. Moisture transfer models for slabs drying. International Communications in Heat and Mass Transfer, v. 32, p. 80-93, 2005. 
CORZO O.; BRACHO N.; ALVAREZ C.; RIVAS V.; ROJAS Y. Determining the moisture transfer parameters during the air-drying of mango slices using biot-dincer numbers correlation. Journal of Food Process Engineering, v. 31, p. 853-873, 2008.

DEMIREL, D.; TURHAN M. Air-drying behavior of Dwarf Cavendish and Gros Michel banana slices. Journal of Food Engineering, v. 59, p. 1-11, 2003.

DINCER, I.; DOST, S. An analytical model for moisture diffusion in solid objects during drying. Drying Technology, v. 13, p. 425-435, 1995.

DINCER, I.; DOST, S. A modeling study for moisture diffusivities and moisture transfer coefficients in drying of solid objects. International Journal of Energy Research, v. 20, p. 531-539, 1996.

DINCER, I. Moisture Loss from Wood Products During Drying-Part I: Moisture Diffusivities and Moisture Transfer Coefficients. Energy Sources, v. 20, p. 67-75, 1998.

DINCER I.; HUSSAIN M. M. Development of a new Bi-Di correlation for solids drying. International Journal of Heat and Mass Transfer, v. 45, n. 15, p. 3065-3069, 2002.

DINCER, I.; HUSSAIN, M. M. Development of a new Biot number and lag factor correlation for drying applications. International Journal of Heat and Mass Transfer, v. 47, p. 635-658, 2004.

ERGUNES, G.; TARHAN, S. Color retention of red peppers by chemical pretreatments during greenhouse and open sun drying. Journal of Food Engineering, v. 76, n. 3, p. 446-452, 2006.

GELY, M. C.; SANTALLA, E. M. Moisture diffusivity in quinoa (Chenopodium quinoa Willd.) seeds: Effect of air temperature and initial moisture content of seeds. Journal of Food Engineering, v. 78, n. 3, p. 1029-1033, 2007.

GIOVANELLI, G.; ZANONI, V.; LAVELLI, V.; NANI, R. Water sorption, drying and antioxidant properties of tomato products. Journal of Food Engineering, v. 52, p. 135-141, 2002.

GUINÉ, R. P. F.; BARROCA, M. J.; SILVA, V. Mass transfer properties of pears for different drying methods. International Journal of Food Properties, v. 16, p. 251-262, 2013.

KOC, A. B.; TOY, M.; HAYOGLU, I.; VARDIN, H. Performance of a solar dryer used for red pepper drying. J. Agric. Fac. HR. U., v. 8, n. 2, p. 57-65, 2004.

MRKIĆ, V.; UKRAINCZYK, M.; TRIPALO, B. Applicability of moisture transfer Bi-Di correlation for convective drying of broccoli. Journal of Food Engineering, v. 79, n. 2, p. 640-646, 2007.

SARAVACOS, G. S.; MAROULIS, Z. B. Transport properties of foods. New York: Marcel Dekker, Inc., p. 105-237, 2001.

TRIPATHY, P. P.; KUMAR, S. A methodology for determination of temperature dependent mass transfer coefficients from drying kinetics: Application to solar drying. Journal of Food Engineering, v. 90, n. 2, p. 212-218, 2009.

TSAMI E.; KATSIOTI M. Drying kinetics for some fruits: Predicting of porosity and color during drying. Drying Technology, v. 18, n. 7, p 1559-1581, 2000. 